\title{
The Crystal Structure of Succinylcholine Perchlorate
}

\author{
B I R THE JENSEN
}

\author{
Chemical Laboratory C, The Royal Danish School of Pharmacy, \\ DK-2100, Copenhagen, Denmark
}

\begin{abstract}
Succinylcholine perchlorate crystallizes in space group $P 2_{1} / c$ with a unit cell having dimensions $a=6.537, b=13.67, c=12.69 \AA$, and $\beta=93.3^{\circ} . Z=2$. The structure was solved by the heavy-atom method and refined by full matrix least squares technique to an $R$ index of 0.094 , using 976 diffractometer-collected three-dimensional single crystal $X$-ray diffraction intensity data. The conformation of the succinylcholine ion seems to be essentially independent of the influence of the surrounding ions in this crystal structure, and the conformation of the system $\mathrm{O}-\mathrm{C}-\mathrm{C}-\mathrm{N}^{+}$is gauche. Extreme "thermal" motion is shown by the perchlorate ions.
\end{abstract}

The crystal structure of succinylcholine perchlorate was determined as a part 1 of an investigation ${ }^{1,2}$ of the influence of different surroundings on the conformation of the succinylcholine ion.

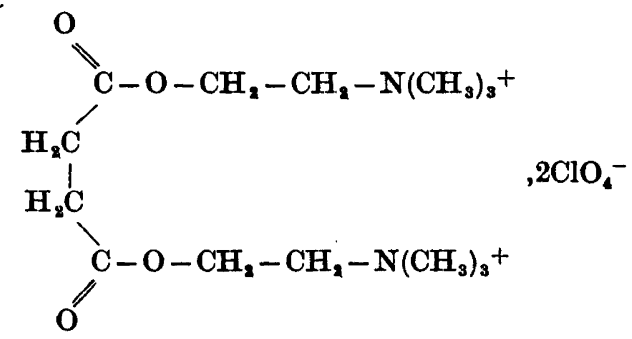

\section{EXPERIMENTAL}

Succinylcholine perchlorate, $\mathrm{C}_{14} \mathrm{H}_{30} \mathrm{Cl}_{2} \mathrm{O}_{12} \mathrm{~N}_{2}$, was prepared by mixing a saturated aqueous solution of succinylcholine chloride with a $2 \mathrm{~N}$ aqueous solution of sodium perchlorate, and the resulting precipitate was purified by recrystallization from ethanol. The crystals show a pronounced tendency to twin-formation, and single crystals were obtained only from aqueous solutions containing $50 \pm 5 \%$ ethanol. M.p. $267-267.5^{\circ} \mathrm{C}$. The crystals are monoclinic needles elongated in the $a$-direction. The unit cell parameters, obtained from precession photographs and from a series of diffractometer-measured $\theta$ values (MoK $\alpha$ radiation, $\lambda=0.7107 \AA$ ) and refined by the least squares method using the program CELSIUS, ${ }^{3}$ are: $a=6.537 \pm 0.004, b=13.67 \pm 0.01, c=12.69 \pm 0.02 \AA$, and $\beta=93.3 \pm 0.1^{\circ}$. The space group is $P 2_{1} / c$. With two formula units per unit cell the calcu- 
lated density is $1.434 \mathrm{~g} / \mathrm{cm}^{3}$, in good agreement with the density of $1.43 \pm 0.01 \mathrm{~g} / \mathrm{cm}^{3}$ measured by flotation in a mixture of tetrachloromethane and toluene. The linear absorption coefficient, $\mu(\mathrm{MoK} \alpha)$, is $3.4 \mathrm{~cm}^{-1}$.

Single crystal $X$-ray diffraction intensities were measured from a crystal of dimensions $0.38 \times 0.5 \times 0.8 \mathrm{~mm}^{3}$ using quartz monochromatized $\mathrm{MoK} \alpha$ incident radiation and a NONIUS 3 circle automatic diffractometer. The $\omega$-scanning mode was used with a scan speed of $0.6^{\circ} / \mathrm{min}$, each reflection being scanned over a range of $1.2^{\circ}$.

Of the 1970 independent reflections within the range of $3^{\circ} \leq \theta \leq 25^{\circ}, 976$ had intensities greater than 2.5 times their corresponding estimated standard deviation and were considered as observed. Unobserved reflections were not included in any calculations.

The diffraction data were reduced to structure amplitudes by the ALGOL-program OUTDIFF-5, written by A. M. Sørensen of this laboratory. No absorption corrections were applied.

\section{DETERMINATION AND REFINEMENT OF THE STRUCTURE}

The structure was solved by the heavy-atom method. The coordinates of the chlorine atom were obtained from the three-dimensional Patterson map, and the positions of six further atoms, $\mathrm{C}(1), \mathrm{C}(2), \mathrm{O}(3), \mathrm{O}(4), \mathrm{N}(7)$ and $\mathrm{C}(10)$ (Fig. 1), were postulated from the three-dimensional Fourier synthesis calculated using phases from the contributions of the chlorine atoms to the structure factors. A second three-dimensional Fourier synthesis based upon the phases from the contributions of all these atoms gave the positions of the rest of the atoms in the succinylcholine ion. The coordinates of the oxygen atoms $\mathrm{O}(11)$ to $\mathrm{O}(14)$ of the perchlorate ion were postulated at the positions of shoulders which could be seen on the electron density peak corresponding to the chlorine atom.

After four cycles of Fourier refinement, in which an overall temperature factor of 3.0 was used, and in which the $R$-value was lowered from 0.45 to 0.39 , the structural parameters were further improved using the full matrix least squares method, firstly in three cycles, varying an overall scale factor and positional coordinates and individual isotropic temperature factors for all atoms which reduced the $R$-value to 0.26 , and then with four further cycles with individual temperature factors for all atoms changed to anisotropic form, after which the $R$-value was 0.11 . A difference Fourier synthesis was then calculated, and from this all the fifteen hydrogen atoms in the asymmetric unit could be located at stereochemically reasonable positions. The conformation about all three $\mathrm{N}-\mathrm{C}\left(\mathrm{H}_{3}\right)$ bonds was staggered as expected. The heights of the peaks on the difference map corresponding to hydrogen atoms were $0.2-0.5$ e $\AA^{-3}$.

In three subsequent cycles of full matrix least squares refinement the contributions of the hydrogen atoms were included, but their parameters were kept constant. Their thermal parameters were assumed to be the same as those of the atoms to which they are bonded. The form factors for all atoms were taken from International Tables for X-Ray Crystallography. ${ }^{4}$ Unit weight was given to each observed reflection except for very weak and very strong amplitudes, which were given weights less than 1.0. The final $R$-value is 0.094 . The observed structure amplitudes and the final calculated structure factors are given in Table 7. Nearly all calculations have been performed on the IBM 7094 computer at the NEUCC installation in Copenhagen using the integrated program system $X-R A Y 63 .^{5}$ 
Table 1. Final atomic positional parameters, and their e.s.d. $\left(\times 10^{4}\right)$ in parentheses.

\begin{tabular}{|c|c|c|c|}
\hline & $x / a$ & $y / b$ & $z / c$ \\
\hline $\mathrm{Cl}(1)$ & $0.0776(4)$ & $0.1363(2)$ & $0.3297(3)$ \\
\hline$O(11)$ & $0.0585(23)$ & $0.2270(13)$ & $0.3212(29)$ \\
\hline$O(12)$ & $0.2905(14)$ & $0.1251(13)$ & $0.3579(10)$ \\
\hline$O(13)$ & $-0.0431(27)$ & $0.0924(15)$ & $0.3947(15)$ \\
\hline$O(14)$ & $0.0545(25)$ & $0.1070(26)$ & $0.2369(13)$ \\
\hline $\mathrm{C}(1)$ & $0.0577(14)$ & $0.5463(8)$ & $0.5087(9)$ \\
\hline$C(2)$ & $0.2490(14)$ & $0.5500(8)$ & $0.4445(8)$ \\
\hline $\mathbf{O}(3)$ & $0.3155(10)$ & $0.4825(6)$ & $0.3987(7)$ \\
\hline $\mathrm{O}(4)$ & $0.3224(9)$ & $0.6403(5)$ & $0.4435(6)$ \\
\hline $\mathrm{C}(5)$ & $0.4957(15)$ & $0.6519(8)$ & $0.3738(11)$ \\
\hline$C(6)$ & $0.5920(14)$ & $0.7464(9)$ & $0.3946(10)$ \\
\hline$N(7)$ & $0.4805(11)$ & $0.8372(6)$ & $0.3526(7)$ \\
\hline $\mathrm{C}(8)$ & $0.3016(20)$ & $0.8580(10)$ & $0.4200(14)$ \\
\hline $\mathrm{C}(9)$ & $0.4208(21)$ & $0.8293(11)$ & $0.2389(11)$ \\
\hline$C(10)$ & $0.6312(20)$ & $0.9212(20)$ & $0.3670(12)$ \\
\hline $\mathrm{H}(11)$ & $-0.042(-)$ & $0.608(-)$ & $0.486(-)$ \\
\hline H(12) & $0.100(-)$ & $0.554(-)$ & $0.592(-)$ \\
\hline $\mathbf{H}(51)$ & $0.603(-)$ & $0.592(-)$ & $0.385(-)$ \\
\hline $\mathrm{H}(52)$ & $0.437(-)$ & $0.650(-)$ & $0.291(-)$ \\
\hline $\mathbf{H}(61)$ & $0.611(-)$ & $0.753(-)$ & $0.481(-)$ \\
\hline $\mathbf{H}(62)$ & $0.743(-)$ & $0.745(-)$ & $0.365(-)$ \\
\hline $\mathbf{H}(\mathbf{8 1})$ & $0.350(-)$ & $0.865(-)$ & $0.500(-)$ \\
\hline $\mathbf{H}(82)$ & $0.225(-)$ & $0.805(-)$ & $0.438(-)$ \\
\hline $\mathbf{H}(83)$ & $0.200(-)$ & $0.915(-)$ & $0.390(-)$ \\
\hline $\mathrm{H}(91)$ & $0.525(-)$ & $0.805(-)$ & $0.172(-)$ \\
\hline $\mathrm{H}(92)$ & $0.350(-)$ & $0.755(-)$ & $0.250(-)$ \\
\hline H(93) & $0.350(-)$ & $0.880(-)$ & $0.188(-)$ \\
\hline $\mathbf{H}(101)$ & $0.600(-)$ & $1.000(-)$ & $0.360(-)$ \\
\hline $\mathrm{H}(102)$ & $0.740(-)$ & $0.950(-)$ & $0.430(-)$ \\
\hline $\mathrm{H}(103)$ & $0.740(-)$ & $0.915(-)$ & $0.290(-)$ \\
\hline
\end{tabular}

Table 2. Final atomic thermal parameters, and their e.s.d. in parentheses. The anisotropic temperature factors are defined by the equation

$$
\left.\mathrm{T}_{\mathrm{j}}=\exp -\frac{1}{6}\left(h^{2} a^{* 2} B_{11}+k^{2} b^{* 2} B_{22}+l^{2} c^{* 2} B_{33}+2 h k a^{*} b^{*} B_{12}+2 h l a^{*} c^{*} B_{13}+2 k l b^{*} c^{*} B_{23}\right)\right]
$$

\begin{tabular}{|c|c|c|c|c|c|c|}
\hline Atom & $B_{11}$ & $B_{22}$ & $B_{33}$ & $B_{18}$ & $B_{13}$ & $B_{23}$ \\
\hline $\mathrm{Cl}(1)$ & $2.79(.10)$ & $5.46(.15)$ & $5.39(.14)$ & $-0.11(.12)$ & $0.65(.09)$ & $0.43(.14)$ \\
\hline$O(11)$ & $7.3(0.8)$ & $9.5(1.0)$ & $62.8(5.0)$ & $3.5(0.8)$ & $5.8(1.6)$ & $7.8(1.8)$ \\
\hline$O(12)$ & $4.5(0.5)$ & $22.4(1.5)$ & $13.1(0.9)$ & $3.0(0.7)$ & $-0.5(0.5)$ & $4.7(1.0)$ \\
\hline $\mathrm{O}(13)$ & $17.3(1.3)$ & $23.1(1.7)$ & $21.0(1.5)$ & $-5.2(1.3)$ & $15.1(1.3)$ & $2.8(1.3)$ \\
\hline$O(14)$ & $12.2(1.1)$ & $53.8(4.0)$ & $9.8(0.9)$ & $-14.2(1.7)$ & $2.5(0.7)$ & $-13.7(1.7)$ \\
\hline $\mathrm{C}(1)$ & $2.9(0.4)$ & $4.6(0.5)$ & $5.6(0.6)$ & $-0.9(0.4)$ & $1.7(0.4)$ & $-0.9(0.5)$ \\
\hline$C(2)$ & $2.7(0.4)$ & $3.4(0.5)$ & $4.6(0.5)$ & $-0.0(0.4)$ & $0.5(0.4)$ & $0.6(0.4)$ \\
\hline$O(3)$ & $3.8(0.3)$ & $4.6(0.4)$ & $8.0(0.5)$ & $0.0(0.3)$ & $2.5(0.3)$ & $-0.9(0.4)$ \\
\hline$O(4)$ & $2.6(0.3)$ & $4.3(0.4)$ & $6.8(0.4)$ & $0.3(0.3)$ & $1.8(0.3)$ & $1.1(0.3)$ \\
\hline $\mathrm{C}(5)$ & $3.1(0.5)$ & $4.7(0.6)$ & $9.9(0.8)$ & $0.3(0.4)$ & $3.8(0.5)$ & $1.2(0.6)$ \\
\hline$C(6)$ & $2.4(0.4)$ & $5.2(0.6)$ & $7.8(0.7)$ & $0.2(0.4)$ & $1.0(0.4)$ & $1.0(0.6)$ \\
\hline$N(7)$ & $2.9(0.3)$ & $3.7(0.4)$ & $5.4(0.5)$ & $-0.5(0.3)$ & $1.0(0.3)$ & $0.5(0.3)$ \\
\hline $\mathrm{C}(8)$ & $6.3(0.7)$ & $5.2(0.7)$ & $14.3(1.2)$ & $2.1(0.6)$ & $6.6(0.8)$ & $1.4(0.8)$ \\
\hline C(9) & $6.9(0.7)$ & $8.9(1.0)$ & $6.0(0.7)$ & $-2.1(0.7)$ & $-1.7(0.6)$ & (1.6)9.7) \\
\hline $\mathrm{C}(10)$ & $6.2(0.7)$ & $5.0(0.7)$ & $8.6(0.8)$ & $-3.4(0.6)$ & $0.3(0.6)$ & $-0.3(0.6)$ \\
\hline
\end{tabular}




\section{DESCRIPTION AND DISCUSSION OF THE STRUCTURE}

The final structural parameters, together with their estimated standard deviations, are given in Tables 1 and 2 , and the interatomic distances and angles are shown in Tables 3 and 4.

Table 3. Bond lengths, and their e.s.d. $\left(\times 10^{2}\right)$ in parentheses. $\mathrm{Cl}-\mathrm{O}$ distances calculated assuming riding motion of the oxygen atoms on $\mathrm{Cl}(1)$ are also given.

\begin{tabular}{|c|c|c|}
\hline & $\AA$ & $\underset{\AA}{\text { Corrected value }}$ \\
\hline$C\left(1^{\prime}\right)-C(1)$ & $1.48(1)$ & \\
\hline$C(1)^{\prime}-C(2)$ & $1.53(1)$ & \\
\hline $\mathrm{C}(2)-\mathrm{O}(3)$ & $1.19(1)$ & \\
\hline $\mathrm{C}(2)-\mathrm{O}(4)$ & $1.32(1)$ & \\
\hline$O(4)-C(5)$ & $1.49(1)$ & \\
\hline$C(5)-C(6)$ & $1.45(2)$ & \\
\hline $\mathrm{C}(6)-\mathrm{N}(7)$ & $1.52(1)$ & \\
\hline$N(7)-C(8)$ & $1.52(2)$ & \\
\hline $\mathrm{N}(7)-\mathrm{C}(9)$ & $1.48(2)$ & \\
\hline $\mathrm{N}(7)-\mathrm{C}(10)$ & $1.52(1)$ & \\
\hline $\mathrm{Cl}(1)-\mathrm{O}(11)$ & $1.25(2)$ & 1.57 \\
\hline $\mathrm{Cl}(1)-\mathrm{O}(12)$ & $1.43(1)$ & 1.55 \\
\hline $\mathrm{Cl}(1)-\mathrm{O}(\mathbf{1 3})$ & $1.32(2)$ & 1.54 \\
\hline $\mathrm{Cl}(1)-\mathrm{O}(14)$ & $1.25(2)$ & 1.56 \\
\hline
\end{tabular}

Table 4. Bond angles, $\left({ }^{\circ}\right)$, and their e.s.d. in parentheses.

$\begin{array}{ll}\mathrm{C}\left(1^{\prime}\right)-\mathrm{C}(1)-\mathrm{C}(2) & 112(1) \\ \mathrm{C}(1)-\mathrm{C}(2)-\mathrm{O}(3) & 125(1) \\ \mathrm{C}(1)-\mathrm{C}(2)-\mathrm{O}(4) & 110(1) \\ \mathrm{O}(3)-\mathrm{C}(2)-\mathrm{O}(4) & 125(1) \\ \mathrm{C}(2)-\mathrm{O}(4)-\mathrm{C}(5) & 113(1) \\ \mathrm{O}(4)-\mathrm{C}(5)-\mathrm{C}(6) & 109(1) \\ \mathrm{C}(5)-\mathrm{C}(6)-\mathrm{N}(7) & 118(1) \\ \mathrm{C}(6)-\mathrm{N}(7)-\mathrm{C}(8) & 109(1) \\ \mathrm{C}(6)-\mathrm{N}(7)-\mathrm{C}(9) & 112(1) \\ \mathrm{C}(6)-\mathrm{N}(7)-\mathrm{C}(10) & 106(1) \\ \mathrm{C}(8)-\mathrm{N}(7)-\mathrm{C}(9) & 113(1) \\ \mathrm{C}(8)-\mathrm{N}(7)-\mathrm{C}(10) & 108(1) \\ \mathrm{C}(9)-\mathrm{N}(7)-\mathrm{C}(10) & 109(1) \\ O(11)-\mathrm{Cl}(1)-\mathrm{O}(12) & 103(1) \\ O(11)-\mathrm{C}(1)-\mathrm{O}(13) & 117(2) \\ O(11)-\mathrm{C}(1)-\mathrm{O}(14) & 103(2) \\ O(12)-\mathrm{C}(1)-\mathrm{O}(13) & 114(1) \\ O(12)-\mathrm{C}(1)-\mathrm{O}(14) & 105(1) \\ O(13)-\mathrm{Cl}(1)-\mathrm{O}(14) & 114(1)\end{array}$

In the perchlorate ions the oxygen atoms have very high thermal parameters (cf. Table 2 and Fig. 1), and the bond lengths and angles deviate somewhat (cf. Table 3) from those of the regular tetrahedron with ideal $\mathrm{Cl}-\mathrm{O}$ distances of $1.46 \AA .8$ If interatomic distances are not corrected for thermal motion, Acta Chem. Scand. 25 (1971) No. 9 


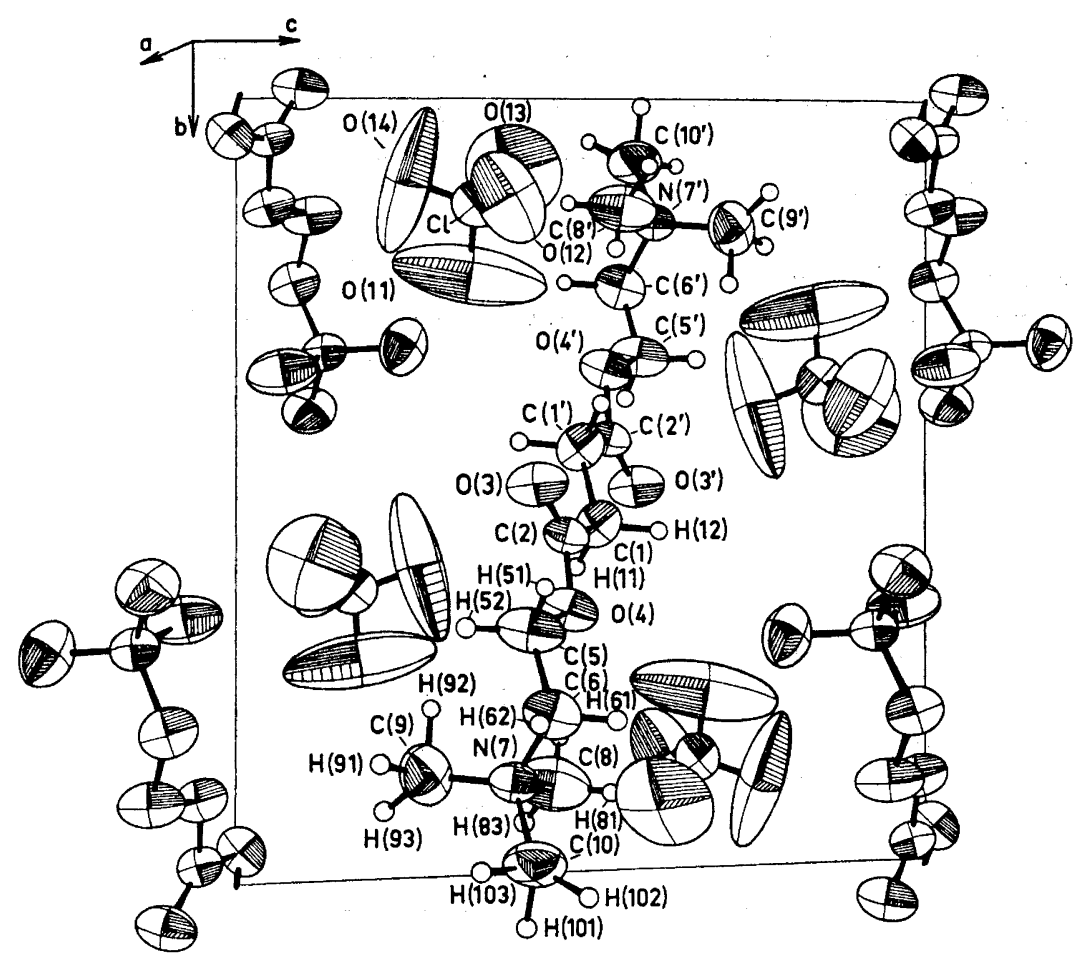

Fig. 1. The structure of succinylcholine perchlorate viewed in perspective along the $a$-axis. The $50 \%$ probability thermal ellipsoids calculated from the final thermal parameters of the least squares refinement are drawn for the non hydrogen atoms, while spheres of an arbitrary size are drawn for the hydrogen atoms. The atomic numbering used in this paper is shown. The drawing was produced by ORTEP.11

the observed mean separation is generally shorter than the real mean distance between the atoms. ${ }^{9,10}$ Hence, when approximate corrections for the "thermal motion" were calculated assuming "riding motion" of the oxygen atoms on the chlorine atoms, calculated $\mathrm{Cl}-\mathrm{O}$ bond lengths of about $1.55 \AA$ (Table 3) were obtained. These are greater than any reported $\mathrm{Cl}-\mathrm{O}$ distances in perchlorate ions and may indicate that the ellipsoidal representation of the oxygen atoms assumed in the refinement is unsatisfactory. Some refinements using fractional perchlorate oxygen atoms in multiple sites were performed, but these gave results which clearly had no physical meaning. The thermal ellipsoids of two of the oxygen atoms, $O(11)$ and $O(14)$, indicate large vibrational amplitudes of these atoms in preferred directions. This may have physical meaning, suggesting oscillation of each perchlorate ion with the oscillation axis centered in $\mathrm{Cl}(1)$ and perpendicular to the plane $\mathrm{O}(11)-$ $\mathrm{Cl}(1)-\mathrm{O}(14)$.

In this structure each succinylcholine ion has a rather extended conformation. The backbone is not completely planar but has a shallow twist ( $c f$. Table 5 which lists the deviations of the backbone atoms from the plane through the 
Table 5. Deviations of atoms from the plane through the central atoms in the succinylbackbone, $\mathrm{C}(1), \mathrm{C}(2), \mathrm{C}\left(1^{\prime}\right)$, and $\mathrm{C}\left(2^{\prime}\right)$.

\begin{tabular}{lc}
\hline Atom & Deviation $(\AA)$ \\
\hline $\mathrm{O}(3)$ & -0.18 \\
$\mathrm{O}(4)$ & 0.29 \\
$\mathrm{C}(5)$ & 0.45 \\
$\mathrm{C}(6)$ & 0.48 \\
$\mathrm{~N}(7)$ & 1.76 \\
\hline
\end{tabular}

central atoms $\mathrm{C}(1), \mathrm{C}(2), \mathrm{C}\left(1^{\prime}\right)$, and $\left.\mathrm{C}\left(2^{\prime}\right)\right)$. The atomic arrangement in the ester group is planar within the experimental limits, and $\mathrm{C}(5)$ and the $\beta$-carbon atom in the acid moiety, $\mathrm{C}\left(1^{\prime}\right)$, are $s$-cis to the carbonyl group. This is the most common ester conformation ${ }^{6}$ but in the related structure of succinylcholine iodide $^{2}$ a more unusual conformation was found about the ester groups.

Fig. 2. The conformation of the system $\mathrm{O}-\mathrm{C}-\mathrm{C}-\mathrm{N}^{+}$, as viewed down the bond $\mathrm{C}(5)-\mathrm{C}(6)$. The dihedral angle is given.

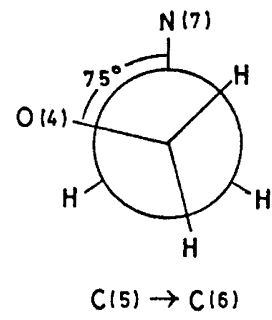

The system $\mathrm{O}-\mathrm{C}-\mathrm{C}-\mathrm{N}^{+}$has the usual gauche conformation, ${ }^{7}$ the dihedral angle $\mathrm{O}(4)-\mathrm{C}(5)-\mathrm{C}(6)-\mathrm{N}(7)$ being $75^{\circ}$ (Fig. 2) and the intramolecular distances $\mathrm{N}(7) \cdots \mathrm{O}(4), \mathrm{C}(8) \cdots \mathrm{O}(4)$, and $\mathrm{H}(82) \cdots \mathrm{O}(4)$ being $3.13,2.99$, and $2.34 \AA$, respectively.

Table 6. Distances $(\AA)$ between atoms that are less than the sum of the respective van der Waals radii, excluding those within a single chain.

$\begin{array}{lll}\mathrm{C}(1)_{(x, y, x)} & \cdots \mathrm{O}(14)_{\left(-x, \frac{1}{2}+y, \frac{1}{2}-z\right)} & 3.27 \\ \mathrm{C}(5)_{(x, y, z)} & \cdots \mathrm{O}(12)_{\left(1-x, \frac{1}{2}+y, \frac{1}{2}-z\right)} & 3.28 \\ \mathrm{C}(2)_{(x, y, z)} & \cdots \mathrm{O}(14)_{\left(-x, \frac{1}{2}+y, \frac{1}{2}-z\right)} & 3.05 \\ \mathrm{C}(8)_{(x, y, z)} & \cdots \mathrm{O}(13)_{(-x, 1-y, 1-z)} & 3.05 \\ \mathrm{C}(10)_{(x, y, z)} & \cdots \mathrm{O}(13)_{(1+x, 1+y, z)} & 3.17 \\ \mathrm{O}(3)_{(x, y, z)} & \cdots \mathrm{C}(9)_{\left(1-x, y-\frac{1}{2}, \frac{1}{2}-z\right)} & 3.28\end{array}$

The molecular packing is not very compact, and the few close intermolecular contacts ( $\leq$ the sum of the respective van der Waals radii) are listed in Table 6. Four out of the six are of interionic character: the negative charge of the perchlorate ion and the positive charge of the quaternary ammonium group are delocalized from the chlorine and nitrogen atom, respectively, and the carbonyl carbon atom $\mathrm{C}(2)$ has a fractional positive charge. Nevertheless

Acta Chem. Scand. 25 (1971) No. 9 
Table 7. Observed structure amplitudes and calculated structure factors for succinylcholine perchlorate. The column headings are the index $l,\left|F_{\mathrm{o}}\right|(\times 10)$ and $\left|F_{\mathrm{c}}\right|(\times 10)$.

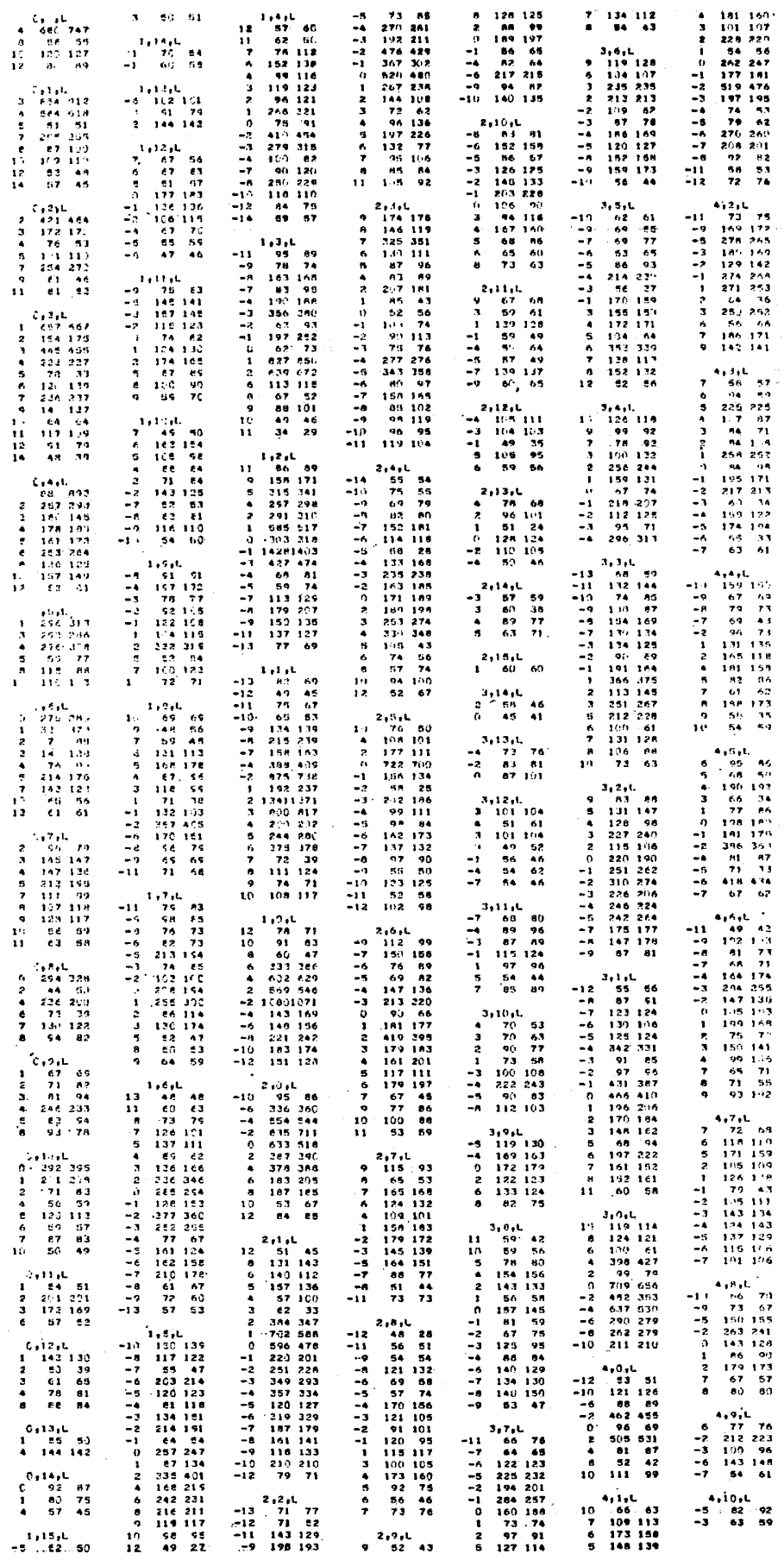


Table 7. Continued

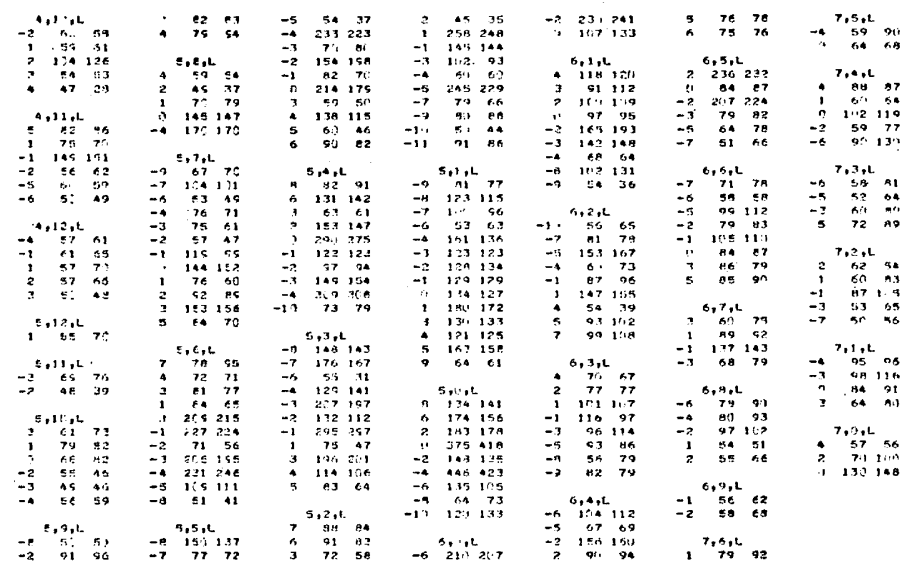

ionic forces seem to be much less dominant in the present structure than in the structure of succinylcholine iodide ${ }^{2}$ and the conformation of the succinylcholine ion in succinylcholine perchlorate is apparently essentially independent of the influence of the surrounding ions.
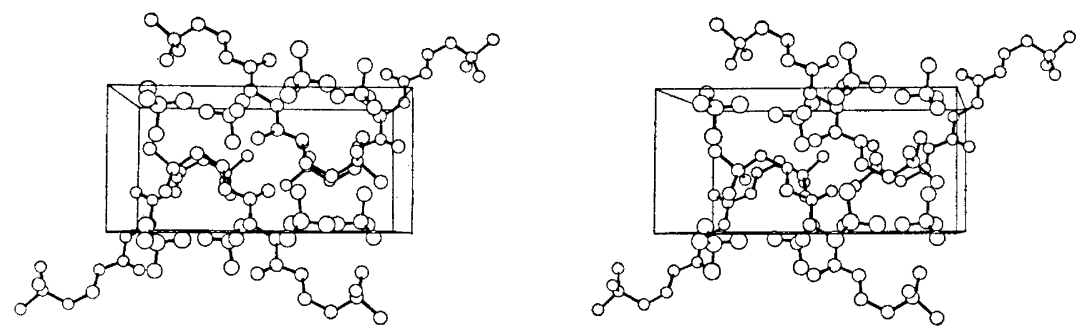

Fig. 3. Stereodiagrams of the succinylcholine perchlorate structure viewed along the $c$-axis. The atoms are represented by spheres of arbitrary sizes.

Acknowledgements. The author wishes to thank the head of the laboratory, Professor Bodil Jerslev, for her kind interest in this work. The Laboratory is greatly indebted to Statens almindelige Videnskabsfond for the diffractometer.

\section{REFERENCES}

1. Jensen, B. Acta Chem. Scand. 22 (1968) 2035.

2. Jensen, B. Acta Chem. Scand. 24 (1970) 2517.

3. Liminga, R. Acta Chem. Scand. 19 (1965) 1631.

4. International Tables for X-Ray Crystallography, Kynoch Press, Birmingham 1962 , Vol. III.

5. Stewart, J. M. X-RAY 63, Technical Report Tr 64-6, NSG-398, Computer Science Center of the University of Maryland, College Park 1964.

Acta Chem. Scand. 25 (1971) No. 9 
6. Mathieson, A. McL. and Welsh, H. K. Acta Cryst. 18 (1965) 953.

7. Sundaralingam, M. Nature 217 (1968) 35.

8. Cruickshank, D. W. J. J. Chem. Soc. 19615486.

9. Busing, W. R. and Levy, H. A. Acta Cryst. 17 (1964) 142.

10. Johnson, C. K. In Crystallographic Computing, Munksgaard, Copenhagen 1970, p. 220.

11. Johnson, C. K. ORTEP, A Fortran Thermal Ellipsoid Plot Program for Crystal Structures, U.S. Atomic Energy Commission Publication ORNL-3794, 1966.

Received February 20, 1971.

Acta Chem. Scand. 25 (1971) No. 9 